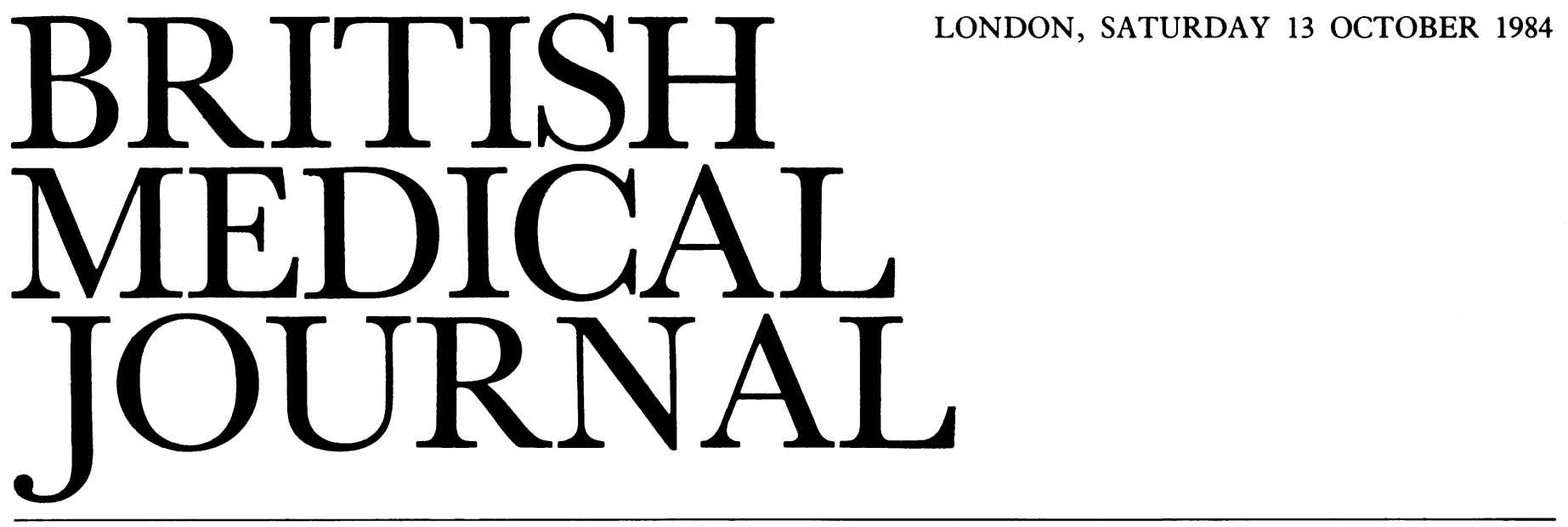

\title{
Informed consent in surgical trials
}

There is not much difficulty in allocating a patient at random to one or other arm of a controlled clinical trial when the relative merits of the two treatments for the disease are unknown and neither the investigator nor the patient perceives any difference between them. True, obtaining informed consent (however that phrase is defined ${ }^{1}$ ) still requires an effort by the doctor and acquiescence by the patient, but few patients will have much difficulty in accepting randomisation when each treatment seems not to bestow a disadvantage and one might possibly carry an advantage.

Things are different, however, when the treatments offered vary considerably in their effects on the patient, as an important study by Taylor and her colleagues has shown. ${ }^{2}$ They were alerted by slow recruitment to a trial which aimed at comparing segmental mastectomy, this operation plus radiotherapy, and total mastectomy in the management of operable breast cancer. Three and a half years from the start of the trial-in which a group of interested and committed clinicians participated-only a sixth of the expected accrual rate had been achieved. Accordingly a questionnaire which included the opportunity for open ended responses was circulated, and the replies showed a remarkable variety of reasons why either none or only some of the surgeon's patients had been enrolled. There was a $97 \%$ response rate, itself an indication of the participants' interest, and most dominant in the reasons given was concern with the doctor-patient relationship in such a randomised clinical trial $(73 \%)$. Next, and one would guess interlinked, was "trouble with informed consent." There were also some who feared that they would bear a moral responsibility to patients in arm A or B if $\mathrm{C}$ turned out (as they expected it might) to be as good but without the negative qualities of the other two.

These observations on real life as distinct from the ideal world of trial design raise many problems. I concentrate here on only two. The first is the doctor's role in relation to his patient and vice versa. Many years ago William James said that the doctor does more by the moral force of his presence than by any other means (though he excepted surgery in certain instances) and clearly in the trial under consideration this bothered both patients and surgeons. On the one hand, the patients often wished for a personal decision by their medical adviser rather than for an invitation to be spun on a roulette wheel. On the other hand, surgeons felt emasculated by having to voice uncertainty, in the interests of a scientific approach, and by their inability to distinguish the merits of different courses of action. As the authors put it: "for surgeons accustomed to the classical organisation of medical practice, the clinical trial with random assignment ... is an unfamiliar and disquieting process often prompting non-participation." The question may well be asked, If this is so then are we justified in conducting clinical trials as distinct from looking at other ways of making our knowledge reliable? Marcia Angell rightly states that not all problems have solutions, by which she implies solutions that can be supported by an established canon of scientific or other thought. ${ }^{3}$ We may well have found an example of this in relation to controlled trials in circumstances when perceived outcomes are so disparate.

The second point relates to that philosophical itch, or perhaps running sore, informed consent. ${ }^{1}$ Inevitably informed consent must be incomplete: a patient does not possess as much information as his medical attendant, nor can he be dispassionate about his own illness. A doctor perceives this and may be uncomfortable with his own attempts to inform and with the implied or overt admission of uncertainty of treatment in his own mind. He may also fear the impact of information about the illness on both the patient's psyche and his or her response to the illness; this has been used as an argument for not telling patients all that they need to know to give consent. ${ }^{4}$ In a trial comparing mastectomy with excision of a lump if the null hypothesis is the appropriate starting point (as clinical trialists usually though not consistently maintain), then to explain this to the patient and go on to say that she should be randomised, perhaps to lose her breast "unnecessarily" requires mental gymnastics beyond the abilities of many.

The reverse is also true: surgical tradition and bias may make an innovative but rational lesser procedure unacceptable for fear that it might result in an avoidable death. Of course, committed trialists would argue that surgeons of this persuasion should not take part in trials and are impediments to progress in the search for the greatest happiness for the greatest number. They will also take heart from another opinion poll, which sampled the views of a cross section of the healthy population on participation in clinical trials. ${ }^{5}$ Two thirds said that they would take part 
except in demanding circumstances such as wide local excision versus mastectomy or excision of tumour versus amputation, when about half opted for choosing their own treatment. The study also showed-some would say ominously - that patients had a high level of confidence in the doctor's ability to determine what was wrong and how best it should be treated. Such optimism is obviously now greater than the doctor's self certainty threatened as it is by the scientific imperative of knowing by trial. ${ }^{6}$

Surgeons obviously have difficulties with these matters; surgical clinical trials do introduce a new dimension into the doctor-patient relationship, and this may distort the pattern of recruitment and so the conclusions that can be drawn. Debate of the issues must continue without, one hopes, anyone being overly dogmatic on matters which are incompletely understood and whose consequences have been so little explored.

H A F DUdLEY

Director,

Academic Surgical Unit,

St Mary's Hospital,

London W2 INY

1 Cancer Research Campaign Working Party on Breast Conservation. Informed consent: ethical legal and medical implications for doctors and patients who participate in randomised clinical rials. Br Med f 1983;286:1117-21.

2 Taylor KM, Margolese RG, Soskolne CL. Physicians' reasons for not entering eligible patients in a randomised clinical trial of surgery for breast cancer. N Engl F Med 1984;310:1363-7.

Angell M. Patients' preferences in randomised clinical trials. N Engl f Med 1984;310:1385-7.

Wikinson AW. Consent. In: Duncan AS, Dunstan GR, Welbourn RB, eds. Dictionary of medical

survey. Clin Oncol 1984;10:155-61.

Dudley HAF. The controlled clinical trial and the advance of reliable knowledge: an outsider looks in. Br Med f 1983;287:957-60.

\section{Diagnosis of vitamin $B_{12}$ deficiency}

"What was once relatively straightforward, seems lately to have become more confusing" wrote Lindenbaum last year, referring to the diagnosis of megaloblastic anaemia. ${ }^{1}$ The comment applies particularly to the investigation of deficiency of vitamin $\mathrm{B}_{12}$ (cobalamin), the basis of which has been changed by the introduction of automated red cell counters. Whereas formerly the inquiry concerned a patient with megaloblastic anaemia, mental disturbance, or neuropathy, now it is as frequently triggered by the chance finding of a raised mean red cell volume. Macrocytosis may be found in about one in every 25 routine blood counts, commonly without anaemia, ${ }^{2}$ and of these perhaps one in 20 is related to deficiency of cobalamin. ${ }^{23}$ The only practical way of assessing the cobalamin state of patients in a general hospital is by measuring the serum concentration. This used to be determined by microbiological assay, but a dozen commercial kits have brought the radioisotope dilution assay to most laboratories. The dangerous non-specificity of the binder in some of the earlier systems ${ }^{4}$ has been corrected, ${ }^{5}$ but falsely low results may now be generated..$^{6-8}$ The limitations of the serum assay have been reviewed by Beck. ${ }^{9}$ Apart from technical problems, some of which are peculiar to radioisotope dilution assay, high transcobalamin concentrations may produce normal serum concentrations in the presence of cobalamin deficiency ${ }^{10}$ and conditions such as pregnancy may give low serum concentrations in the absence of deficiency. "One of the more important issues, not confined to estimations of cobalamin, is the definition of a reference range. ${ }^{12}$ When measurements of the serum concentration of cobalamin are used as a screening test many low values will be found that cannot be correlated with clinical disease, whether or not there is macrocytosis. ${ }^{8}$

Why then is the radioisotope dilution assay used? Firstly, because it gives useful results in most circumstances where there is already other evidence of vitamin deficiency. The assay will confirm the deficiency and usually differentiate it from folate deficiency. Secondly, the alternative, sensitive methods are unsuitable for the general laboratory; determination of methylmalonic aciduria requires special equipment ${ }^{13}$ and both it and the deoxyuridine suppression test are impracticable in the numbers required. Microbiological assays are not better than radioisotope dilution assays ${ }^{14}$; they appeared to be so only because they were used with more discretion. Furthermore, the clinical importance of a low serum concentration of cobalamin may be assessed by examination of the peripheral blood and the bone marrow, megaloblastic changes usually being obvious even in the early case, ${ }^{15}$ and by noting the response of the mean red cell volume to treatment.

Deficiency of cobalamin may be due to malnutrition or malabsorption; only rarely is it precipitated by increased demand. ${ }^{16}$ Strict vegetarianism is not uncommon among some immigrants, but pernicious anaemia is not confined to the white population. ${ }^{17}$ Both a dietary history and an absorption test are required in patients of all races - with one exception: antibody to intrinsic factor in a patient with a low serum concentration of cobalamin confirms a diagnosis of pernicious anaemia and no absorption test is needed. ${ }^{1}$ Generally, the Schilling test with plasma uptake is a practical combination of absorption tests; a spot faeces test, based on the excretion of isotope in a single sample, may be as accurate. ${ }^{18}$ Because deficiency of either cobalamin or folate may cause malabsorption tests giving inconsistent results should be repeated when the deficiency has been corrected. ${ }^{19}$ Occasionally absorption of protein bound cobalamin may be defective and associated with megaloblastic anaemia. ${ }^{20}$ The effect of intrinsic factor may be shown by using hog intrinsic factor from an opened capsule. ${ }^{21}$ Tests based on the simultaneous administration of radioactively labelled cobalamin with and without intrinsic factor may give misleading and indefinite results, ${ }^{22-24}$ and the results differ when the two isotopes are given separately. ${ }^{25}$

Confusion reigns when imperfect tests are applied indiscriminately, and evaluated individually they lead to confusion: as the clinician sows, he is likely to reap.

D W DAwSON

Consultant Haematologist,

North Manchester General Hospital,

Manchester M8 6RB

1 Lindenbaim J. Status of laboratory testing in the diagnosis of megaloblastic anemia. Blood

2 Davidson RJL, Hamilton PJ. High mean red cell volume: its incidence and significance in routine haematology. I Clin Pathol 1978;31:493-8.

all CA. The application of the tests, singly or in combination, to clinical problems. In: Hall CA 1983:209-16.

Kolhouse JF, Kondo $\mathrm{H}$, Allen NC, Podell E, Allen RH. Cobalamin analogues are present in human plasma and can mask cobalamin deficiency becausecul 5 Fish DI, Dawson DW. Comparison of methods used in commercial kits for the assay of serum vitamin B 12. Clin Lab Haematol 1983;5:271-7.

6 LeFebvre RJ, Virji AS, Mertens BF. Erroneously low results due to high nonspecific binding with a radioassay kit that measures 'true' serum vitamin $B_{12}$. Am J Clin Pathol 1980;74:209-13.

Brynskov J, Andersen K, Gimsing P, Hippe E. False low serum vitamin B 12 values with radiodilution assays using blocked R-binders. Lancet 1983;i:1104-5.

Schilling RF, Fairbanks VF, Miller R, Schmitt K, Smith MJ. 'Improved' vitamin $B_{12}$ assays: a report on two commercial kits. Clin Chem 1983;29:582-3.

Weck Whe assay of serum cobalamin by Lactobacillus leichmannii and the interpretation of serum cobalamin levels. In: Hall CA, ed. The cobalamins. Vol 10. Methods in haematology.

Corcinourgh: Churchill Livingstone, 1983:31-50.

myeloid leukaemia: an experiment of nature involving vite of pernicious anaemia and chronic 1971; 20: $511-20$. 